\title{
SEMIÓTICA LITERARIA Y TEATRAL EN ESPAÑA: ADDENDA BIBLIOGRAFICA V
}

\author{
José Romera Castillo
}

(UNED, Madrid)

De nuevo vuelvo a la carga con otro panorama bibliográfico sobre el tema. Este eslabón de la cadena se une a los que, con anterioridad, he ido trenzando:

1. Semiótica literaria y teatral en España (Kassel: Reichenberger, 1988).

2. «Semiótica literaria y teatral en España: Addenda bibliográfica (I y II)». En Investigaciones Semióticas. III, J. Romera y A. Yllera (eds.), II, 537-561 (Madrid: UNED, 1990).

3. «Semiótica literaria y teatral en España: Addenda bibliográfica III». Discurso 6 (1991), 107-134.

4. «Semiótica literaria y teatral en España: Addenda bibliográfica IV». En Investigaciones Semióticas IV, AES (ed.), II, 1043-1055 (Madrid: Visor Libros, 1992).

Las fichas ahora reseñadas completan los anteriores panoramas, abarcan hasta 1992 y ponen de manifiesto, una vez más, el auge de los estudios semióticos de la literatura y el hecho teatral en España. 


\section{SEMIÓTICA LITERARIA}

\subsection{Teoría}

ABAD, F. (1990a): «Lo literario y la periodización literaria». Tropelias (Universidad de Zaragoza) 1, 13-25.

- (1990b): «Retórica, poética y teoría de la literatura». Estudios Románicos 4, 27-36. [Homenaje al prof. Luis Rubio.]

- (1992): «Peirce, Jakobson y la esencia de la literatura y el lenguaje». Signa. Revista de la Asociación Española de Semiótica 1, 143-151.

ACOSTA ROMERO, Á. (1992): «Del homo loquens al homo semioticus». En Investigaciones Semióticas. IV, AES (ed.), I, 13-20. Madrid: Visor Libros.

Albert Galera, J. (1992): «Semiosis textual y superposición de mundos». En Signs of Humanity/L 'homme et ses signes, G. Deledalle (ed.), I, 535-540. Berlín: Mouton de Gruyter.

ASOCIACIÓN ESPAÑOLA DE SEMIÓTICA, ed. (1992): Investigaciones Semióticas. IV (Describir, inventar, transcribir el mundo). Madrid: Visor Libros, 2 vols.

AUllón de HARO, P. (1992): Teoria del ensayo. Madrid: Verbum.

Bobes NAVES, M. ${ }^{a}$ del C. (1992a): El diálogo. Estudio pragmático, lingüístico y literario. Madrid: Gredos.

- (1992b): Artículo en El silencio, C. Castilla del Pino (ed.): Madrid: Alianza.

Bustos GuADAÑo, E. de (1992): «La metáfora y la filosofia contemporánea del lenguaje». Anthropos 129, 37-42.

CABADA Gómez, M. (1992): «Francisco Ayala, lector paradójico». En Francisco Ayala teórico y crítico literario, A. Sánchez Trigueros y A. Chicharro (eds.), 83-92. Granada: Diputación Provincial.

Cabanilles, A. (1992a): «Bajtín/Medveded/Volosinov: El espacio de la Metalingüistica». En Investigaciones Semióticas. IV, AES (ed.), I, 45-52. Madrid: Visor Libros.

- (1992b): «Rhetoric of Advertising and Semiotics of Discourse». En Signs of Humanity/L'homme et ses signes, G. Deledalle (ed.), I, 467-472. Berlín: Mouton de Gruyter.

Cabo Aseguinolaza, F. (1992a): El concepto de género y la literatura picaresca. Santiago de Compostela: Universidad.

- (1992b): «La Teoría literaria norteamericana actual: Acotaciones desde el margen». Insula 552, 17-18.

CÁCERES SÁNCHEZ, M. (1992): «Semiosis littéraire et procès de communication artistique». En Signs of Humanity/L'homme et ses signes, G. Deledalle (ed.), I, 529-534. Berlín: Mouton de Gruyter.

CALLE, R. de la (1986): «La Literatura y su teoría» y «El hecho teatral». En su obra, Repertorio bibliográfico de investigación estética, 385-448. Valencia: Federico Doménech y Fundación Edivart.

CAMARERo ARribas, T. (1992a): "Lo leible y lo legible: Las modalidades del leer». En Investigaciones Semióticas. IV, AES (ed.), I, 53-57. Madrid: Visor Libros.

- (1992b): «El proyecto generativo de Greimas y el proyecto interpretativo de Eco: Confluencias". En Signs of Humanity/L'homme et ses signes, G. Deledalle (ed.), III, 1511-1516. Berlín: Mouton de Gruyter. 
CANOA GalianA, J. (1992): «La epistemología en la historia literaria». Anthropos 129, 72.

CASTAÑARES, W. (1985): El signo: problemas semióticos y filosóficos. Madrid: Universidad Complutense (Tesis de Doctorado).

- (1987a): «Ch. S. Peirce: historia de una marginación». Revista de Occidente 71.

-_(1987b): «Filosofia pragmática y lógica de la representación-mediación». Revista de Occidente 79, 138-144. [Sobre la antología de Ch. S. Peirce, Obra lógico-semiótica.]

_- (1988): «De la lógica-semiótica y el arte simulatoria». La balsa de la Medusa 5-6, 150-155.

- (1989): «... Y la palabra era el hombre». Revista de Occidente 97, 173-179. [Sobre la antología de Ch. S. Peirce, El hombre, un signo.]

- (1992a): «Algunas consecuencias de dos principios peirceanos». Signa 1, 135-142.

- (1992b): «Peirce en España: panorama bibliográfico». Signa 1, 215-224.

Castilla del Pino, C., ed. (1992): El silencio. Madrid: Alianza.

Chicharro Chamorro, A. (1991): «Acerca del comentario de textos literarios como instrumento docente (Significación actual y perspectivas de futuro)m. Revista de Literatura 106, 585-594.

- (1992): «Bibliografias y estudios generales sobre la semiótica literaria en España». En Investigaciones Semióticas. IV, AES (ed.), I, 69-79. Madrid: Visor Libros.

CuESTA ABAD, J. M. (1992a): «Adversus orthodoxos (el destino de la Teoría de la Literatura)». Anthropos 129, 59-62.

- (1992b): Teoria hermenéutica y literatura (El sujeto del texto). Madrid: Visor.

CuETo, J. (1981): «La "no ficción”». En El año literario español 1980, VV.AA., 73-90. Madrid: Castalia.

DOMINGUEZ CAPARRós, J. (1990): «Materia mitológica y género literario: un ejemplo en Lope de Vega». Tropelias (Universidad de Zaragoza) 1, 91-104. [Basado en el poema narrativo La Andrómeda y la tragicomedia El Perseo.]

- (1992a): «Teoría de la literatura y filosofia analitica». Anthropos 129, 47-50.

- (1992b): «Ch. S. Peirce y la Teoría de la Literatura». Signa 1, 169-178.

DOMínguEZ REY, A. (1992a): «Dinámica del significante en la materia-espejo del lenguaje». Anthropos 129, 31-36.

- (1992b): «Hacia una gramática semiótica». En Investigaciones Semióticas. IV, AES (ed.), II, 887-895. Madrid: Visor Libros.

FRECHILla DÍAZ, E. (1992): «Pragmática e intencionalidad en la literatura infantil». En Investigaciones Semióticas. IV, AES (ed.), II, 623-627. Madrid: Vidor Libros.

GARCÍA BERRIO, A. (1985): «Sociocrítica y formalismo a la luz de las tipologías textuales». En Homenaje a J. A. Maravall, VV.AA., II, 117-128. Madrid: CIS.

- (1991): «La interpretación y sus límites». SABER/Leer 47, 4-5. [Reseña del libro de U. Eco, I limiti dell 'interpretazione. Milán: Bompiani, 1990.]

García Berrio, A. y Huerta Calvo, J. (1992): Los géneros literarios: sistema e historia. Madrid: Cátedra.

García García, J. C. (1992): «El humor: sobre lo trivial y lo trascendental». En Investigaciones Semióticas. IV, AES (ed.), I, 81-88. Madrid: Visor Libros.

GARCÍA-NOBLEJAS SÁNCHEZ-CENDAL, G. (1992): «Traducción, equivalencia y valor textual». En Investigaciones Semióticas. IV, AES (ed.), I, 89-94. Madrid: Visor Libros. 
Garrido Gallardo, M. Á. (1992a): «De que el mono desciende del hombre. Perspectivas actuales de la semiótica». En Introducción a la semiótica, A. Sánchez Trigueros y J. Valles Calatrava (eds.), 13-30. Almería: Instituto de Estudios Almerienses.

- (1992b): «Nominalismo y literatura». Anthropos 129, 55-58.

- (1992c): «A propósito de Peirce: Semiótica. Literatura. Verdad». Signa 1, 163-167.

Garrido Medina, J. (1992): «Nominalismo y literatura». Anthropos 129, 55-58.

GAVALDÁ ROCA, J. V. (1992a): «El principio de alteridad y la concepción bajtiniana del discurso». En Investigaciones Semióticas. IV, AES (ed.), I, 95-100. Madrid: Visor Libros.

- (1992b): «La pensée sémiotique du cercle de Bakhtine». En Signs of Humanity/L'homme et ses signes, G. Deledalle (ed.), III, 1439-1446. Berlín: Mouton de Gruyter.

Gómez Lara, M. J. y Prieto Pablos, J. A. (1991): «Lingüística, Estilística, Estilística aplicada». Presentación de Stylística (Sevilla) 1, 5-10.

GonzÁlez CARRERA, J. A. (1991): «Unamuno inspiró mi juventud» (Entrevista con A. J. Greimas) El Correo Español-El Pueblo Vasco, 10 de mayo, 46.

GONZÁlez SAlVADOR, A. (1984): «De lo fantástico y de la literatura fantástica». Anuario de Estudios Filológicos (Univ. de Extremadura) VII, 207-226.

GRANDE ROSALES, M. Á. (1991): «Retórica y semiótica: hacia una poética general». Epos VII, 583-591. [Reseña de Investigaciones Semióticas III, J. Romera y A. Yllera (eds.), 2 vols.]

- (1992): «Julia Kristeva: la semiótica como modelo isomórfico de la lógica poética». En Investigaciones Semióticas. IV, AES (ed.), I, 113-130. Madrid: Visor Libros.

GuILlÉN, C. (1988): El primer Siglo de Oro. Estudios sobre géneros y modelos. Barcelona: Crítica.

GUIJARRO MORALES, J. L. (1991): «Literatura y lingüística: ¿Matrimonio feliz o pareja desavenida?» Stylística 1, 11-21.

GUTIÉRREZ, F. (1989): «Epifanías del Imaginario: la leyenda». En La Leyenda, antropología, historia y literatura. Madrid: Casa de Velázquez-Universidad Complutense.

Huerta Calvo, J., ed. (1989): Formas carnavalescas en el Arte y la Literatura. Barcelona: Ediciones del Serbal.

LEGUEN, B. (1992): «Descubrimiento del espacio filosófico a través del lenguaje del filósofo Brice Parain». En Investigaciones Semióticas. IV, AES (ed.), I, 131-134. Madrid: Visor Libros.

LINARES ALÉS, F. (1992): «El Ensayo sobre el entendimiento humano [de J. Locke], desde la semiótica». En Investigaciones Semióticas. IV, AES (ed.), I, 135-141. Madrid: Visor Libros.

LLEDó, E. (1992): El silencio de la escritura. Madrid: Centro de Estudios Constitucionales.

LlERA LlORENTE, M.ª del M. (1992): «La estructura sígnica del hombre». En Investigaciones Semióticas. IV, AES (ed.), I, 143-148. Madrid: Visor Libros.

LÓPEZ SÁENZ, M. ${ }^{\text {a }}$ C. (1990): «La dimensión existencial de la semiología de M. Merleau-Ponty». Cuadernos de Investigación Filológica XVI (1-2), 137-152.

Maestro, J. G. (1992a): “La retórica al día». Signa 1, 235-242. [Reseña de Investigaciones Semióticas. III.] 
- (1992b): «Sistematización y aplicación literaria de una tipología del discurso verbal». En Signs of Humanity/L'homme et ses signes, G. Deledalle (ed.), I, 449-458. Berlín: Mouton de Gruyter.

ManTEIGA PousA, S. (1992): «Valor de los objetos en el realismo matafísico». En Investigaciones Semióticas. IV, AES (ed.), I, 161-165. Madrid: Visor.

MARTínez EXPósito, A. (1992a): «Diachronic Perspective and Literary Competence». En Signs of Humanity/L homme et ses signes, G. Deledalle (ed.), I, 567-574. Berlin: Mouton de Gruyter.

- (1992b): «El descubrimiento de los "ismos" (Cómo expresar la novedad)». En Investigaciones Semióticas. IV, AES (ed.), I, 167-173. Madrid: Visor Libros.

MARTínez RoMERO, C. (1989): El pensamiento teórico literario español (1965-1975). Granada: Universidad.

MARTínez VÁzQUEZ, M. y MORA, M. J. (1991): «Reading comprehension y análisis estilístico: posibilidades metodológicas». Stylistica 1, 91-99.

MARTOS ELICHE, F. (1992): «Semiótica de la cultura y revistas literarias. Las Españas. Revista Literaria (1946-1956)». En Investigaciones Semióticas. IV, AES (ed.), II, 685-690. Madrid: Visor Libros.

MilláN, J. A. (1990): «En torno al concepto de intertextualidad». En Europa en España, España en Europa. Simposium Internacional de Literatura Comparada. Universidad de Aquisgrán-Universidad de Navarra-Barcelona: PPU.

MuÑoz Romero, M. ${ }^{a}$ (1990): «Operaciones de repérage en el texto literario». Philologia Hispalensis 5, 39-50.

NADAL GARCíA, J. M. a (1991): «La semiótica como forma de vida: el valor de la obra de Greimas». Era. Revista Internacional de Semiótica I (1-2), 167-200.

Nubiola, J. (1992): «Peirce en España y España en Peirce». Signa 1, 225-231.

NúÑEz RAMOS, R. (1992): «El juego y la experiencia de los mundos posibles». En Investigaciones Semióticas. IV, AES (ed.), I, 437-442. Madrid: Visor Libros.

OCHANDO MADRIGAL, E. (1992): «El lector en la obra literaria». Ensayos (Revista de la E.U.F.P. de Albacete) 7, 121-127.

OKARIZ, A. (1991): «La única moral válida es la defensa de las minorías» (Entrevista con A. J. Greimas). Egin, 10 de mayo, 47.

PENEDO Picos, A. (1992): «Hacia una redefinición del objeto literario». Anthropos $129,28-30$.

PEÑA-ARDID, C. (1992): Literatura y cine. Madrid: Cátedra.

PÉrez CARreño, F. (1988a): «Una ocasión perdida». La balsa de la Medusa 5-6, 155-161.

PÉREZ DE TUdelA, J. (1988): El pragmatismo americano. Acción racional y reconstrucción del sentido. Madrid: Cincel.

PORRAS MEDRANO, A. (1992): «Hacia una competencia descriptiva». En Investigaciones Semióticas. IV, AES (ed.), I, 189-196. Madrid: Visor Libros.

Posada Alonso, C. (1992): «De la imagen al espectáculo». En Investigaciones Semióticas. IV, AES (ed.), I; 455-460. Madrid: Visor Libros.

Pozuelo Yvancos, J. M. (1992a): «Una crítica descentrada». Anthropos 129, 43-46.

— (1992b): «La Teoría Literaria reencuentra la ficción». Ínsula 552, 11-12.

PulIDO, G. (1992): «Un modelo de análisis: François Rabelais visto por Mijail Bajtin». En Investigaciones Semióticas. IV, AES (ed.), I, 197-203. Madrid: Visor Libros. 
QUINTANA DocIO, F. (1992): «El signo intertextual ante el lector real (jugando con fuego)». En Investigaciones Semióticas. IV, AES (ed.), I, 205-214. Madrid: Visor Libros.

RAMÓN TRIVES, E. (1992): «La isotopía por identificación como instrumento de la producción/interpretación textual (A propósito de la Constitución política de los Estados Unidos Mexicanos)». En Investigaciones Semióticas. IV, AES (ed.), I, 215222. Madrid: Visor Libros.

RAMOS, A. (1991): «Relectura semiótica de la mímesis en la producción artística». Era. Revista Internacional de Semiótica I (1-2), 131-141.

RESINA, J. R. (1991): Los usos del clásico. Barcelona: Anthropos.

REVISTA Estudios de Lengua y Literatura francesas (1990), de la Universidad de Cádiz $(K 10),{ }^{\circ} 4$ [ N. ${ }^{\circ}$ monográfico sobre Análisis del relato. El punto de vista.]

REVISTA Textos (1990), de Zaragoza. N. ${ }^{\circ}$. correspondiente al año 1988 sobre Mito-ficción-lecturas.

REVista Signa (1992), de la Asiociación Española de Semiótica. N.o 1, monográfico sobre Ch. S. Peirce y la literatura (Actas del I Seminario Internacional de Literatura y Semiótica), coordinado por J. Romera, A. Yllera y R. Calvet.

RODRÍGUEZ PEQUEÑo, M. (1992): «La semiótica en el empirismo inglés». En Investigaciones Semióticas. IV, AES (ed.), I, 223-227. Madrid: Visor Libros.

Romera CASTILlo, J. (1991): «Sistemas no verbal y verbal en literatura». Face. Revista de Semiótica e Comunicaçao (São Paulo) 1, 75-91.

- (1992a): «Introducción a la semiótica (Notas bibliográficas)». En Introducción a la semiótica, A. Sánchez Trigueros y J. Valles Calatrava (eds.), 1-11. Almería: Instituto de Estudios Almerienses.

- (1992b): «Semiótica literaria y teatral en España: Addenda bibliográfica IV». En Investigaciones Semióticas. IV, AES (ed.), II, 1043-1055. [«Teoría», 1043-1046.]

Romera Castillo, J.; Yllera, A. y Calvet, R., eds. (1992): Ch. S. Peirce y la literatura. Número monográfico de Signa 1.

ROYANO GUTIÉRREZ, L. (1992): «La función del lector». En Investigaciones Semióticas. IV, AES (ed.), I, 229-235. Madrid: Visor Libros.

RUBIO MARTín, M. a (1992): «La obra literaria y sus límites: transtextualidad y transrealidad, dos formas de textualidad». En Investigaciones Semióticas. IV, AES (ed.), I, 237-242. Madrid: Visor Libros.

RuIz, E. (1992): Hacia una semiologia de la escritura. Madrid: Fundación Germán Sánchez Rupérez.

SAlABERT, P. (1992): «Sublimación de lo cotidiano. El hombre sin signos». Signs of Humanity/L'homme et ses signes, G. Deledalle (ed.), I, 235-243. Berlin: Mouton de Gruyter.

SÁNCHEZ MECA, D. y Domínguez CAPARRós, J., eds. (1992): Filosofia y Literatura. Historia de una relación e interna reflexión critica. Anthropos 129 (número monográfico).

SÁnchez Trigueros, A. y Chicharro Chamorro, A., eds. (1992): Francisco Ayala teórico y crítico literario. Granada: Diputación Provincial.

SiRvent Ramos, M. Á. (1990): Roland Barthes. De las críticas de interpretación al análisis textual. Alicante: Universidad.

- (1992): La teoria textual barthesiana. Murcia: Universidad.

SUÁrez DUQUE, V. (1992): «Heterotopía como ficción. El pensamiento del Afuera». En Investigaciones Semióticas. IV, AES (ed.), I, 259-265. Madrid: Visor Libros. 
URBINA FONTURBEL, R. (1992): «Aspectos pragmáticos en la reflexión teórico-literaria de Francisco Ayala». En Francisco Ayala teórico y critico literario, A. Sánchez Trigueros y A. Chicharro (eds.), 371-378. Granada: Diputación Provincial.

URRUTIA, J. (1992): Literatura y comunicación. Madrid. Instituto de España/EspasaCalpe.

USANDIZAGA LLEONART, H. (1991): «La formación semiótica del lector escolar». Signos 3.

UTRERA, R. (1987): Literatura cinematográfica. Cinematografia literaria. Sevilla: Alfar.

VÁzQuez Medel, M. Á. (1991a): «Hacia una nueva Teoría de la Comunicación (I)». TTC. Revista de Información Bibliográfica en Teoría y Tecnología de la Comunicación (Sevilla) 0, 43-48.

- (1991b): «Hacia una estilística transtextual de la identidad y la diferencia». Stylistica 1, 23-31.

- (1992a): El dinamismo textual. Introducción a la Semiótica transdiscursiva. Sevilla: Cuadernos de Comunicación.

- (1992b): «Francisco Ayala: teoría literaria vs. teoría de la comunicación». En Francisco Ayala teórico y crítico literario, A. Sánchez Trigueros y A. Chicharro (eds.), 109-123. Granada: Diputación Provincial.

VERJAT, A., ed. (1989): El retorno de Hermes: hermenéutica y ciencias humanas. Barcelona: Anthropos.

Vicente Gómez, F. (1992): «La relevancia de la semiótica de Ch. S. Peirce en la constitución de una pragmática de la literatura». Signa 1, 153-161.

VILARNovo, A. (1991): «Teorías explicativas de la coherencia textual». Revista Española de Lingüística 21.1, 125-144.

VILlanUeVA, D. (1992a): «La fenomenología literaria de Francisco Ayala». En Francisco Ayala teórico y crítico literario, A. Sánchez Trigueros y A. Chicharro (eds.), 167-177. Granada: Diputación Provincial.

-(1992b): Teorias del realismo literario. Madrid: Instituto de España/Espasa-Calpe.

- (1992c): «Teoría Literaria y enseñanza de la literatura». Ínsula, 552, 1-2.

WAHNON, S. (1992): «Una mirada crítica a la posmodernidad». Ínsula 552, 9-10. [Sobre La posmodernidad y Mijail Bajtin. Una poética dialógica, de Iris M. Zavala.]

YLLERA, A. (1992a): «La semiótica entre los discursos». En Introducción a la semiótica, A. Sánchez Trigueros y J. Valles Calatrava (eds.), 31-49. Almería: Instituto de Estudios Almerienses.

- (1992b): «Juego de palabras/Juego de imágenes». En Signs of Humanity/L 'homme et ses signes, G. Deledalle (ed.), II, 827-832. Berlín: Mouton de Gruyter.

\subsection{Narrativa}

Albaladejo, T. (1992): Semántica de la narración: la ficción realista. Madrid: Taurus.

Álvarez SANAGuSTín, A. (1992a): «Teoría narrativa y fabulación en Francisco Ayala». En Francisco Ayala teórico y crítico literario, A. Sánchez Trigueros y A. Chicharro (eds.), 187-198. Granada: Diputación Provincial. 
- (1992b): «La descripción insólita». En Investigaciones Semióticas. IV, AES (ed.), II, 517-523. Madrid: Visor Libros.

ArA Torralba, J. C. y HÜBER TEICHGrÄBER, D. (1992): «Estrategias de la enunciación en las novelas de Juan Valera». Revista de Literatura 108, 599-618.

ARIZA, M. (1992): «Estudios de variantes del cuento de Caperucita». En Investigaciones Semióticas. IV, AES (ed.), II, 525-536. Madrid: Visor Libros.

BAAMONDE TRAVERSO, G. (1992): «Indianos y gachupines: Análisis intertextual». En Investigaciones Semióticas. IV, AES (ed.), II, 537-543. Madrid: Visor Libros. [Sobre La Regenta y Tirano Banderas.]

BAÑos, F. (1992): «El Arcipreste de Talavera como hagiógrafo (La moralización, más allá de la reprobación)». En Actas II Congreso Internacional de la Asociación Hispánica de Literatura Medieval, J. M. Lucía Megías et alii (eds.), I, 175-185. Alcalá de Henares: Universidad.

Barrado Belmar, M. ${ }^{a}$ del C. (1992): «Marco Polo-Ítalo Calvino: Semiótica de las ciudades en Le Città invisibili». En Investigaciones Semióticas. IV, AES (ed.), II, 545-554. Madrid: Visor Libros.

BARrio MARCo, J. M. (1990): Ernst Heminguay. Su dinámica narrativa. Valladolid: Universidad.

BELTRÁN AlmeríA, L. (1990): «La enunciación narrativa: El narrador y la voz dual». Tropelias 1, 27-41.

- (1992): Palabras transparentes. La configuración del discurso del personaje en la novela. Madrid.

Beltrán Almería, L. y VARGas García, J. (1991): «El discurso del personaje en la novela galdosiana». Revista de Literatura 106, 513-534.

BENÍTEZ, R. (1992): La literatura española en las obras de Galdós (Función y sentido de la intertextualidad) Murcia: Universidad.

Bobes Naves, M. ${ }^{a}$ C. (1992a): «Filosofía y construcción de la novela». Anthropos $129,50-55$.

- (1992b): «Teorias sobre la novela en Francisco Ayala». En Francisco Ayala teórico y crítico literario, A. Sánchez Trigueros y A. Chicharro (eds.), 23-38. Granada: Diputación Provincial.

Bobes NAVES, J. (1992): «Los conceptos de tiempo y espacio en Francisco Ayala». En Francisco Ayala teórico y crítico literario, A. Sánchez Trigueros y A. Chicharro (eds.), 321-334. Granada: Diputación Provincial.

CABo AseguinolazA, F. (1992a): El concepto de género y la literatura picaresca. Santiago: Universidad.

- (1992b): «Realidad, ficción y autobiografia: A propósito de Miguel de Castro». En Investigaciones Semióticas. IV, AES (ed.), II, 587-594. Madrid: Visor Libros.

CÁCERES SÁNCHEZ, M. (1992): «Relato audiovisual y relato literario: para una narratología comparada». Investigaciones Semióticas. IV, I, 299-307. Madrid: Visor Libros.

CARRERo ERAS, P. (1990): Españoles y extranjeros. Última narrativa. Estudios de critica literaria. Salamanca: Universidad.

COBos CASTRO, E. (1989): «Ductilidad y contingencias de la transtextualidad. Reflexiones en torno a Al fin se paga todo (Maria de Zayas), L'Adultère innocent (Scarron) y Le Philtre (Stendhal)». Investigación franco-española 1, 67-99.

CRESPO MATELLÁN, S. (1992): «Descubrir/Describir/Narrar. La Historia verdadera de la conquista de la Nueva España, de Bernal Díez del Castillo». En Investigaciones Semióticas. IV, AES (ed.), II, 999-1008. Madrid: Visor Libros. 
CRUZ GIRÁldEZ, M. (1991): «Zumalacárregui de Galdós: estructura y sentido». Revista de Humanidades (UNED, Sevilla) 2, 111-131.

CUESTA ABAD, J. M. (1991): «El Quijote, novela moderna (Algunas cuestiones de poética histórica)». Epos VII, 335-352.

DíAZ, E. (1989): «Estrategias narrativas en Grafitti de Julio Cortázar». Romance Notes $29,99-106$.

— (1990): “"Duelo" y "Viator": ironía y parodia en los relatos de Juan Benet». ALEC $15,13-28$.

- (1992a): Del pasado incierto. La narrativa breve de Juan Benet. Madrid: Editorial Complutense.

- (1992b): «El espacio fantástico en dos narraciones benetianas: TLB y Reichenau». Lucanor, 55-63.

DiEGO, R. de (1992): «Marguerite Duras: Más allá de la realidad o la invención de la literatura». En Investigaciones Semióticas. IV, AES (ed.), II, 605-613. Madrid: Visor Libros.

Domínguez Caparrós, J. (1992): «Teoría de los estilos en Muertes de perro». En Francisco Ayala teórico y crítico literario, A. Sánchez Trigueros y A. Chicharro (eds.), 143-154. Granada: Diputación Provincial.

ESPEJO CALA, C. (1992): «Las mil y una mentiras de Borges». En Investigaciones Semióticas. IV, AES (ed.), II, 629-632. Madrid: Visor Libros.

EzAMA GIL, Á. (1988): «Juan Ochoa: hacia una comprensión del relato breve». Estudios Humanísticos Filología (León) 10, 163-186.

- (1992): El cuento de la prensa y otros cuentos. Aproximación al estudio del relato breve entre 1890 y 1900. Zaragoza: Universidad.

FORTES, J. A. (1990): La nueva narrativa andaluza. Una lectura de sus textos. Barcelona: Anthropos.

García Collado, M. ${ }^{\text {a }}$ Á. (1992a): «Modernidad de los tradicionales contadores de cuentos». En Investigaciones Semióticas. IV, AES (ed.), II, 615-621. Madrid: Visor Libros.

- (1992b): «Las modalidades factitivas en El Buscón». En Signs of Humanity/L'homme et ses signes, G. Deledalle (ed.), II, 693-698. Berlín: Mouton de Gruyter.

GARCÍA LARRAÑAGA, M. ${ }^{a}$ A. (1991): «Las estructuras narrativas en Clara d'Ellebeuse y Almaide d'Etremont de Francis Jammes. Semejanzas y diferencias». Cuadernos de Investigación Filológica XVII, 19-33.

García Ramos, J. M. (1982): La narrativa de Manuel Puig. La Laguna: Universidad.

GARCíA VElASCO, A. (1992): «El disputado voto del señor Cayo: Técnica narrativa, lenguaje y contemporaneidad». En Miguel Delibes. El escritor, la obra y el lector, C. Cuevas García (ed.), 247-255. Barcelona: Anthropos.

GARrido Domínguez, A. (1992): «El discurso del tiempo en el relato de ficción». Revista de Literatura 107, 5-45.

Gómez REDondo, F. (1981): «El prólogo del Cifar: realidad, ficción poética». Revista de Filología Española LXI, 85-112.

- (1989a): «Terminología genérica en la Estoria de España alfonsí». Revista de Literatura Medieval I, 53-75.

- (1989b): «Historiografia medieval: constantes evolutivas de un género». En Anuario de Estudios Medievales (Estudios ofrecidos a don Emilio Sáez, III) 19, 3-15. 
- (1992): «Géneros literarios en la Estoria de España alfonsí». En Actas del II Congreso Internacional de la Asociación Hispánica de Literatura Medieval, J. M. Lucía Megías et alii (eds.), I, 383-393. Alcalá de Henares: Universidad.

GonZÁlez LANDA, M. ${ }^{a}$ C. (1992): «Signos reiterados en La soledad era esto» [de J. J. Millás]. En Investigaciones Semióticas. IV, AES (ed.), II, 633-642. Madrid: Visor Libros.

GONZÁlez SAlVADOR, A. (1988): «Anabase: analecture». Anuario de Estudios Filológicos 10.

- (1989): «Fantastique et fiction (L'Eve future de Villiers de l'Isle-Adam I)». En Villiers de l'Isle-Adam: l'home, la realitat, la ficció, M. Giné i Janer (ed.), 199-209. Lérida: Publicaciones del Estudi General de Lleida.

Gullón, G. (1983): La novela como acto imaginario. Madrid: Taurus.

Gullón, R. (1976): Edición de La incógnita, de B. Pérez Galdós. Madrid: Taurus.

- (1977): Edición de Realidad, de B. Pérez Galdós. Madrid: Taurus.

GutiÉRrez, F. (1992): Cómo leer a Juan José Millás. Madrid: Júcar.

HERNÁNDEZ ÁlvAREZ, V. (1989): «Les mots de Sartre, psychoanalyse et intertextualité». Estudios Franceses 5, 97-102.

HeRnÁNDEZ VAlCÁRCEL, C. y EsCudero MARTÍNEZ, C. (1986): La narrativa lirica de Azorín y Miró. Alicante: Caja de Ahorros de Alicante y Murcia.

HerRERO, I. (1990): «L'ambigüité du point du vue dans Ingénue Saxancour de Rétif de la Bretonne». Etudes Rétiviennes 13, 21-40.

HuICI, N. A. (1992): «Jorge Luis Borges, teoría y práctica de la intertextualidad». En Investigaciones Semióticas. IV, AES (ed.), II; 663-678. Madrid: Visor Libros.

IBEAS VuelTA, N. (1991): "Tras las huellas del personaje ausente en la novela policiaca». Stvdivm. Filologia (Teruel) 7, 87-97.

LEGUEN, B. (1992): «Les objets en tant que signes dans un roman de Balzac: L'Interdiction). En Signs of Humanity/L'homme et ses signes, G. Deledalle (ed.), II, 743750. Berlin: Mouton de Gruyter.

LÓPEZ RODRÍGUEZ, M. a S. (1992): «La "Diferencia” de Robin Vote: Hacia una lectura deconstruccionista de El Bosque de la Noches) [de D. Barnes]. En Investigaciones Semióticas. IV, AES (ed.), II, 679-683. Madrid: Visor Libros.

LUENGO AlBURQUERQUE, E. (1989): La literatura fantástica en Bélgica durante el siglo XX: las recurrencias narrativas. Cáceres: Universidad de Extremadura.

MARIÑO, A. (1989): «La trascendencia en lo fantástico». En Villiers de l'Isle-Adam. l'home, la realitat, la ficció, Marta Giné (ed.), 211-228. Lérida: Estudi General.

MARTín MORÁN, J. M. (1992): Semiótica de una traición recuperada. Génesis poética de «Reivindicación del conde don Julián». Barcelona: Anthropos.

MARTÍNEZ ARNALDOS, M. (1987-89): «La ironía y la sátira como estructura narrativa: J. Belda». Estudios Románicos (Murcia) 5 (Homenaje al profesor Luis Rubio. II), 807-833.

MaRtínez GALÁN, R. (1990): Arte y técnica en la narrativa de Gabriel Miró («Nuestro padre San Daniel» y «El obispo leproso»). Cádiz: Universidad.

MENA, J. C. (1992): «Aspectos de lo fantástico en la narrativa breve de Gonzalo Suárez: La resurrección». Lucanor 8, 65-91.

MONTERREY RodRíGUEZ, J. F. (1989): La voz narrativa en las novelas de Muriel Spark. La Laguna: Universidad. [Resumen de tesis de doctorado. Tesis de doctorado en microfichas.] 
Montolíu DurÁn, E. (1992): Gramática de la caracterización en Valle-Inclán. Análisis sintáctico, pragmático y textual de algunos mecanismos de caracterización. Barcelona: PPU.

MORA GONZÁLEZ, L. (1992): «Manhattan/Bronx, dos realidades neoyorquinas: El espacio narrativo en The Bonfire of the Vanities, de Tom Wolfe». En Investigaciones Semióticas. IV, AES (ed.), II, 691-697. Madrid: Visor Libros.

Navajas, G. (1985): «El diálogo y el yo en Retahilas de Carmen Martín Gaite». Hispanic Review 53.I, 25-39.

- (1986-87): «Retórica de la novela posmodernista española». Siglo XX-20th Century 4, 1-2, 16-26.

- (1987a): Teoria y práctica de la novela posmoderna española. Barcelona: Ediciones del Mall.

- (1987b): «La jerarquía, la letra y lo oral en Paradox, rey de Pío Baroja». Modern Language Notes, marzo, 255-273.

NAVASCUÉS, J. de (1992): «Adán Buenosayres» una novela total (Estudio narratológico) [de Leopoldo Marechal]. Pamplona: EUNSA.

ORTIZ, J. (1990): «Las funciones del discurso y sus consecuencias en Trois Contes de Flaubert». Textos, 65-83.

PAREDES NÚÑEZ, J. (1984): «El término "cuento" en la literatura románica», Bulletin Hispanique 86, 435-51.

- (1986): “"Novella". Un término y un género para la literatura románica». Revista de Filología Románica 4, 125-140.

- (1988): «Del cuento y sus desenlaces». Lucanor. Revista del cuento literario, mayo, 103-114.

- (1992a): «La estructura del cuento medieval: el marco narrativo». En Actas II Congreso Internacional de la Asociación Hispánica de Literatura Medieval, J. M. Lucía Megías et alii (eds.), II, 609-618. Alcalá de Henares: Universidad.

- (1992b): «El sentido de estructura narrativa en Francisco Ayala: el relato breve». En Francisco Ayala teórico y crítico literario, A. Sánchez Trigueros y A. Chicharro (eds.), 179-186. Granada: Diputación Provincial.

PAREDES NúÑEZ, J., ed. (1986): Formas narrativas breves en la literatura románica medieval: problemas de terminología. Granada: Universidad.

PARrilla García, C. (1992a): "La narratio en la Crónica incompleta de los Reyes Católicos». En Actas II Congreso Internacional de la Asociación Hispánica de Literatura Medieval, J. M. Lucía Megías et alii (eds.), II, 619-629. Alcalá de Henares: Universidad.

- (1992b): “"Acrescentar lo que de suyo está crescido": El cumplimiento de Nicolás Núñez». En Historias y ficciones: Coloquio sobre la literatrura del siglo $X V$, R. Beltrán et alii (eds.), 241-253. Valencia: Universitat.

Paz Gago, J. M. a (1992): «Realismo, realidad y ficción realista». En Investigaciones Semióticas. IV, AES (ed.), II, 707-711. Madrid: Visor Libros.

PElÁEz Benitez, D. (1992): «Funciones del narrador en la Crónica de don Álvaro de Luna». En Actas II Congreso Internacional de la Asociación Hispánica de Literatura Medieval, J. M. Lucía Megías et alii (eds.), II, 631-641. Alcalá de Henares: Universidad.

Pérez-Bustamante Mourier, A. S. (1992): «Poética de lo imaginario y héroe novelesco: Hermes en la novela Vidas y fugas de Fanto Fantini, de Álvaro Cunqueiro». En Investigaciones Semióticas. IV, AES (ed.), II, 713-722. Madrid: Visor Libros. 
PÉREZ PÉrez, J. J. (1989): Los cuentos de Mario Benedetti. La Laguna: Universidad. [Resumen de tesis de doctorado y Tesis de doctorado en microfichas.]

PÉreZ PÉreZ, M. ${ }^{a}$ C. (1992): «A través del cuerpo. Metonimia y ensoñación». En Investigaciones Semióticas. IV, AES (ed.), II, 723-732. Madrid: Visor Libros. [Sobre tres novelas de G. Bernanos.]

PÉrez Priego, M. Á. (1992): «La escritura proverbial de Santillana». En Actas II Congreso Internacional de la Asociación Hispánica de Literatura Medieval, J. M. Lucía Megías et alii (eds.), II, 643-651. Alcalá de Henares: Universidad.

PoPA-LisseAnU, D. (1992): «Cuando las piedras hablan». En Signs of Humanity/L'homme et ses signes, G. Deledalle (ed.), II, 751-758. Berlín: Mouton de Gruyter.

Posada Alonso, C. (1992): «El circuito de la comunicación en el relato». En Signs of Humanity/L 'homme et ses signes, G. Deledalle (ed.), II, 647-656. Berlín: Mouton de Gruyter.

Pozuelo Yvancos, J. M. ${ }^{a}$ (1990): «Tetralogía de la soledad: Introducción a la narrativa de Javier Tomeo». Tropelias 1, 177-198.

PRADO, J. del (1988a): Introducción a la edición de Un amor de Swann. Madrid: Cátedra.

- (1988b): «Proust y la necesidad hermenéutica». Barcarola 29, 159-183.

PrIETo Grande, M. ${ }^{\text {a }}$ (1992): «Las reglas del juego: Una lectura lúdica de Julio Cortázar». En Investigaciones Semióticas. IV, AES (ed.), II, 733-740. Madrid: Visor Libros.

RAmón TRIVES, E. (1979): «San Manuel Bueno, mártir, de don Miguel de Unamuno: Análisis macrosémico-predicatorial». En su obra, Aspectos de semántica lingüistico-textual. Madrid: Istmo.

Recio MiR, A. (1992): «San Manuel Bueno, mártir: Variantes textuales, análisis y valoración». En Investigaciones Semióticas. IV, AES (ed.), II, 741-754. Madrid: Visor Libros.

RIBERA LLOPIS, J. M. (1992): «Intertextualidad y literariedad: las Cròniques catalanas, texto confluyente». En Actas II Congreso Internacional de la Asociación Hispánica de Literatura Medieval, J. M. Lucía Megías et alii (eds.), II, 683-690. Alcalá de Henares: Universidad.

RODRÍGUEZ FERNÁNDEZ, C. (1992): «Tipología estructural y contaminación genérica en las Pasiones». En Actas II Congreso Internacional de la Asociación Hispánica de Literatura Medieval, J. M. Lucía Megías et alii (eds.), II, 723-744. Alcalá de Henares: Universidad.

RODRÍGUEZ LÓPEZ-VÁZQUEZ, A. (1992): «Imagen, hipertelia y semiosis en Góngora y Lezama». En Investigaciones Semióticas. IV, AES (ed.), II; 755-761. Madrid: Visor Libros.

RoDRÍGuez PEQUEÑo, M. (1990): «Mundo ficcional y mundo real efectivo en La balsa de piedra de José Saramago». Tropelias 1, 215-218.

Romera CASTILlo, J. (1992): «Semiótica literaria y teatral en España: Addenda bibliográfica IV». En Investigaciones Semióticas. IV, AES (ed.), II, 1043-1055. [«Narrativa), 1046-1050.]

RUANO LEÓN, J. (1991-92): «Narratividad y discursividad. El invierno en Lisboa, de Antonio Muñoz Molina». Almirez (UNED, Córdoba) 1, 22-31.

RUBIO MONTANER (1991): «La tercera persona desde la focalización interna: su equivalencia con la narración en primera persona». Epos VII, 235-257. 
- (1992): «Equivalencias entre primera y tercera personas en la función narrativa». En Investigaciones Semióticas. IV, AES (ed.), II, 981-988. Madrid: Visor Libros.

Ruiz GrandA, E. (1992): «Logique narrative et temporalité». En Signs of Humanity/L 'homme et ses signes, G. Deledalle (ed.), I, 507-512. Berlín: Mouton de Gruyter.

SÁNCHEZ FERNÁNDEZ, A. (1992): «El mito de Dánae: Un ejemplo en la novela erótica». En Investigaciones Semióticas. IV, AES (ed.), II, 775-783. Madrid: Visor Libros. [Sobre Un hombre solo, de Rafael López de Haro.]

SÁNCHEZ GARCÍA, E. (1992): "Visiones del Mediterráneo en el siglo XVI (La Suma de Geografia y El viaje de Turquia». En Investigaciones Semióticas. IV, AES (ed.), II, 1015-1024. Madrid: Visor Libros.

SÁNCHEZ-MESA MARTÍNEZ, D. (1992): «La carnavalización en la crítica y en la narrativa de Francisco Ayala). En Francisco Ayala teórico y crítico literario, A. Sánchez Trigueros y A. Chicharro (eds.), 301-319.

SÁNCHEZ TRIGUEROS, A. (1992): «El comentario textual como procedimiento narrativo: el narrador-crítico de El Hechizado». En Francisco Ayala teórico y crítico literario, 275-285. Granada: Diputación Provincial.

SEgarra MonTANER, M. (1992): «Los símbolos de la verticalidad en la obra de Henri Michaux». En Investigaciones Semióticas. IV, AES (ed.), II, 785-794. Madrid: Visor Libros.

SENABRE, R. (1992): «Teoría y práctica de la novela en Francisco Ayala». En Francisco Ayala teórico y critico literario, A. Sánchez Trigueros y A. Chicharro (eds.), 391-403. Granada: Diputación Provincial.

SERRANO AlONSO, J. (1992): «Una aproximación a los cuentos de Valle-Inclán». Insula 552, 8-9. [Sobre Narraciones breves de Ramón del Valle-Inclán, de R. Alicia Ramos y La ficción breve de Valle-Inclán. Hermenéutica, de Luis T. González del Valle.]

Serrano Sanz, E. (1992): "Genotexto y fenotexto (Desde el relato del Génesis a los actuales contextos)». En Investigaciones Semióticas. IV, AES (ed.), II, 795-801. Madrid: Visor Libros.

SOLÁ SOLÉ, P. (1989): «La enunciación en L'Intersigne de Villiers». En Villiers de l'Isle-Adam: l'home, la realitat, la ficció, M. Giné i Janer (ed.), 135-144. Lérida: Estudi General de Lleida.

Sotelo VÁzQuez, A. (1992): «Hacia un estudio formal de la narrativa del siglo XIX». Insula 546, 5-6.

SPANG, K. (1991): «Novela y metanovela. Observaciones acerca de Fragmentos de Apocalipsis de Gonzalo Torrente Ballester». Revista de Literatura 106, 555-583.

SUÁREZ, M. ${ }^{a}$ P. (1992): «El espacio como soporte de la acción. El episodio de Gauvain en Le conte du Graal». En Investigaciones Semióticas. IV, AES (ed.), I, 251-254. Madrid: Visor Libros.

SUÁREz COAlla, $\mathrm{F}^{\mathrm{a}}$ (1992): «El suspense en la ficción literaria». En Investigaciones Semióticas. IV, AES (ed.), II, 803-808. Madrid: Visor Libros.

URBINA, E. (1991): El sin par Sancho Panza: parodia y creación. Barcelona: Anthropos.

URRUtia, J. (1977): «Introducción» a la edición de La familia de Pascual Duarte, de C. J. Cela. Barcelona: Planeta.

- (1991): «Estructura, significación y sentido de La voluntad». En Dai Modernismi alle Avanguardie (Atti del Convegno dell'Associazione degli Ispanisti Italiani), C. Prestigiacomo y M. ${ }^{a}$ C. Ruta (eds.), 41-52. Palermo: Flaccovio Editore. 
UsAndizaGA, H. (1992): «Las figuras espaciales en un relato de J. M. Arguedas: Arquetipos de la verticalidad y dualismo andino». En Investigaciones Semióticas. $I V$, AES (ed.), II, 837-843. Madrid: Visor Libros.

Valles Calatrava, J. (1992): «Cuento y novela en Francisco Ayala: similitudes y diferencias». En Francisco Ayala teórico y crítico literario, A. Sánchez Trigueros y A. Chicharro (eds.), 379-388. Granada: Diputación Provincial.

VARIOS AUTORES (1987): La narrativa: cinema y literatura. Barcelona: Fundació Caixa Pensions.

VÁzQuez MEdel, M. Á. (1992): «Serniótica del encubrimiento/Semiótica del descubrimiento». En Investigaciones Semióticas. IV, AES (ed.), II; 1033-1039. Madrid: Visor Libros.

VIÑUALES, P. P. (1992): «Mi entierro de Clarín: un cuento raro». Anales de Literatura Española de la Universidad de Alicante 8, 193-206.

YLLERA, A. (1992): «¿Reiventar la cultura o descubrir al otro?» En Investigaciones Semióticas. IV, AES (ed.), I, 267-274. Madrid: Visor Libros. [Analiza varios textos narrativos.]

\subsection{Poesía}

Álvarez SANAgustín, A. (1992): "Análisis textual de "La aurora" de Lorca». En Introducción a la semiótica, A. Sánchez Trigueros y J. Valles Calatrava (eds.), 95-115. Almería: Instituto de Estudios Almerienses.

ANSÓN ANADÓN, A. (1991): «Cinepoema: secuencias de un sueño de vanguardia». Iris (Montpellier), 1-14.

- (1992a): «L'écriture des objets. Poésie et image de l'avant-garde». Mélusine (Cahiers du Centre de Recherches sur le Surréalisme) XIII, 309-317. [N. ${ }^{\circ}$ monográfico sobre Le surréaliste et son psy, coordinado por Anne-Marie Amiot y editado en París: L'Age d'Homme.]

- (1992b): «Imágenes y tempos. Poesía cinematográfica». En Investigaciones Semióticas. IV, AES (ed.), I, 285-291. Madrid: Visor Libros.

BARrera LóPez, J. M. a (1992): «Pragmática del signo poético en Juan de Mena». En Investigaciones Semióticas. IV, AES (ed.), II, 555-561. Madrid: Visor Libros.

Bellido NAVARRo, P. (1992): "Transtextualidad en la poesía de Blas de Otero». En Investigaciones Semióticas. IV, AES (ed.), II, 563-571. Madrid: Visor Libros.

BRUÑA CUEVAS, M. (1992): «Los mensajes escritos en la literatura medieval francesa). En Investigaciones Semióticas. IV, AES (ed.), II, 573-585. Madrid: Visor Libros.

CAMARERO, J. (1989a): «Les hétérogrammes de Georges Perec, contrepoint formel du lyrisme». Queste 4, 49-65.

- (1989b): «Un cas d'intertextualité inscriptive dans La vie mode d'emploi de Georges Perec». Cuadernos de Filología Francesa 3, 25-38.

CARDONA, Á. (1992): «Introducción al estudio de los signos temporales en la lengua poética: hacia un nuevo planteamiento en el estudio de los géneros literarios». En Investigaciones Semióticas. IV, AES (ed.), II, 595-604. Madrid: Visor Libros.

DíAZ NAVARRo, E. (1989): «Algunos aspectos formales y conceptuales en la Égloga III de Garcilaso». Explicación de Textos Literarios 18, 17-25. 
DOMÍNGUEZ CAPARRÓS, J. (1992a): «Semiótica de la poesía». En Introducción a la semiótica, A. Sánchez Trigueros y J. Valles Calatrava (eds.), 71-94. Almería: Instituto de Estudios Almerienses.

- (1992b): «Razones para la oscuridad poética». Revista de Literatura 108, 553-573.

Domínguez REY, A. (1992): «Lenguaje como figura. Análisis semiótico de un poema». Signa 1, 179-187.

García BERrio, A. (1987): “¿Qué es lo que la poesía es?». Lingüistica Española Actual IX (2), 177-188.

- (1989): «La lecture lyrique». Versus 52-53, 71-80.

- (1990): «Cuadros y poemas: Una síntesis de reflexión metodológica sobre la obra de Luis Feito». Tropelias 1, 105-133.

Girón AlCONCHEL, J. L. (1989a): Las formas del discurso referido en el "Cantar de Mio Cid». Madrid: Real Academia Española.

- (1989b): «Enunciación y estilo épico en el Libro de buen amor: algunos aspectos de la polifonía textual». Dicenda 8, 53-70.

- (1992): «Sobre la lengua poética de Berceo: el estilo indirecto libre en Los Milagros». En Actas II Congreso Internacional de la Asociación Hispánica de Literatura Medieval, J. M. Lucía Megías et alii (eds.), I, 367-381. Alcalá de Henares: Universidad.

Gordillo Vázquez, M. ${ }^{a}$ C. y Muro Meléndez-Valdés, M. ${ }^{a}$ P. (1992): «Análisis de los "círculos" en Juan de Mena». En Investigaciones Semióticas. IV, AES (ed.), II, 643-648. Madrid: Visor Libros.

LóPEZ-CASANOVA, A. (1992): "Construcción imaginativa en las Coplas de Jorge Manrique». En Historias y ficciones: Coloquio sobre la literatura del siglo $X V, \mathrm{R}$. Beltrán et alii (eds.), 197-202. Valencia: Universitat.

Maestro, J. G. (1992): «Pragmática de la lírica: Teoría de las instancias poéticas (El sujeto interior)». En Investigaciones Semióticas. IV, AES (ed.), I, 149-160. Madrid: Visor Libros.

Muro MElÉndez-VAldÉs, P. y Gordillo VÁzQuez, M. ${ }^{a}$ C. (1992): «Transferencias expresivas en poesía». En Investigaciones Semióticas. IV, AES (ed.), II, 699-706. Madrid: Visor Libros.

Noguerol, F. (1992): «El grado pleno de la escritura (Análisis semiótico de un texto de Joaquín Sabina)». En Investigaciones Semióticas. IV, AES (ed.), I, 429-435. Madrid: Visor Libros.

NúÑEZ RAMOS, R. (1992): La poesía. Madrid: Síntesis.

REYES CANO, R. (1992): "Garcilaso desde la intertextualidad». Ínsula 552, 3. [Sobre Fonti, miti, topoi. Cinque saggi su Garcilaso, de Antonio Gargano.]

Rodríguez LóPEZ-VÁzQUEZ, A. (1992a): “"Romance de la luna, luna"». En Federico García Lorca. Perfiles críticos, K. Reichenberger y A. Rodríguez López-Vazquez (eds.), 81-87. Kassel: Reichenberger.

- (1992b): «Imagen, hipertelia y semiosis en Góngora y Lezama». En Investigaciones Semióticas. IV, AES (ed.), II, 755-761. Madrid: Visor Libros.

ROMERA CASTILlo, J. (1992): «Semiótica literaria y teatral en España: Addenda bibliográfica IV». En Investigaciones Semióticas. IV, AES (ed.), II, 1043-1055. [«Poesía», 1051-1052.]

USANDIZAGA, H. (1992): «Discours poétique et distance énonciative». En Signs of Humanity/L'homme et ses signes, G. Deledalle (ed.), I, 215-220. Berlín: Mouton de Gruyter. 


\section{SEMIÓTICA TEATRAL}

Albert GalerA, J. ${ }^{a}$ (1992): «Mundos dominantes en la obra de García Lorca (La casa de Bernarda Alba)». En Investigaciones Semióticas. IV, AES (ed.), I, 277-284. Madrid: Visor Libros.

ALONSO ALDAMA, J. A. (1992): «Un problema de interacción: hacer-creer y hacer-hacer en La Celestina). En Signs of Humanity/L'homme et ses signes, G. Deledalle (ed.), II, 687-692. Berlín: Mouton de Gruyter.

Álvarez SANagustín, A. (1992): «Hétérogénéité et théâtralité». En Signs of Humanity/L'homme et ses signes, G. Deledalle (ed.), II, 1155-1162. Berlin: Mouton de Gruyter.

Bellido NavarRo, P. (1991): «Texto dramático y visión del mundo en los dramas socialistas de principios de siglo». Stylística 1, 57-70.

BERENGUER, Á. (1992): «El teatro y la comunicación teatral». Teatro. Revista de Estudios Teatrales 1, 155-179.

BoBES NAVES, M. ${ }^{a}$ C. (1990): «Cómo está construida La dama duende, de Calderón». Tropelías 1, 65-80.

Canoa Galiana, J. (1992a): «Lectura de signos en Tres sombreros de copa de M. Mihura (Aplicación del concepto de interpretante)». Signa 1, 189-200.

- (1992b): «Los intereses creados de Benavente como obra simbólica». En Investigaciones Semióticas. IV, AES (ed.), I, 309-317. Madrid: Visor Libros.

- (1992c): «La semiosis en el drama moderno». En Signs of Humanity/L'homme et ses signes, G. Deledalle (ed.), II, 1177-1182. Berlín: Mouton de Gruyter.

CANTAlAPIEDRA, F. (1992a): “"Desflorar el honor” del post-teatro: Análisis semióticom. Teatro. Revista de Estudios Teatrales 1, 227-248.

- (1992b): «Semiótica y problemas de atribución textual». En Investigaciones Semióticas. IV, AES (ed.), I, 59-68. Madrid: Visor Libros.

CANTOS PÉREZ, A. (1992): «Análisis comparativo entre Bola de sebo, de Guy de Maupassant y La diligencia, de John Ford». En Investigaciones Semióticas. IV, AES (ed.), I, 319-325. Madrid: Visor Libros.

CARo VAlverde, M. ${ }^{a}$ T. (1992): «El otro en el texto (La escena de Las ruinas circulares)». En Investigaciones Semióticas. IV, AES (ed.), I, 327-335. Madrid: Visor Libros.

CORREA COBANO, C. (1992): «El teatro del vértigo: sobre la "puesta en escena" de Hamlet Machine, de Heiner Müller». En Investigaciones Semióticas. IV, AES (ed.), I, 347-354. Madrid: Visor Libros.

Delgado, A. (1990): "Texto dramático y voz narrativa». K 10. Estudios de Lengua y Literatura Francesas (Univ. de Cádiz) 4, 19-34.

DIEGO, F. de (1992): «Autonomía del discurso didascálico en el teatro español del siglo XX». En Actas del X Congreso de la Asociación Internacional de Hispanistas, A. Vilanova (ed.), II, 1713-1719. Barcelona: PPU.

DOMÉNECH, R. (1983): «El espacio escénico en las Comedias bárbaras». En Serta Philologica F. Lázaro Carreter, II, 157-170. Madrid: Cátedra.

- (1986): «Realidad y misterio (Notas sobre el espacio escénico en Bodas de sangre, Yerma y La casa de Bernarda Alba). Cuadernos Hispanoamericanos 433-436, 293-310.

FERNÁNDEZ VÁZQUEZ, J. M. a (1992): «Aproximación al teatro de aglomeración». En Investigaciones Semióticas. IV, AES (ed.), I, 373-377. Madrid: Visor Libros. 
FERrER VALls, T. (1992): «El espectáculo profano en la Edad Media: Espacio escénico y escenografia». En Historias y ficciones: Coloquio sobre la literatura del siglo $X V$, R. Beltrán et alii (eds.), 307-322. Valencia: Universitat.

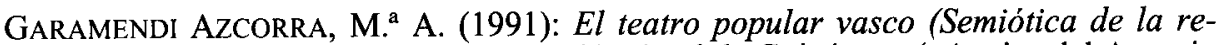
presentación). San Sebastián: Diputación Foral de Guipúzcoa («Anejos del Anuario del Seminario de Filología Vasca», 21).

Gordillo ÁlvarEZ, I. (1992): «Tres crónicas de una muerte anunciada. Discurso literario, filmico y teatral». En Investigaciones Semióticas. IV, AES (ed.), I, 397403. Madrid: Visor Libros.

Guarinos, V. (1992a): Teatro y televisión. Sevilla: Centro Andaluz de Teatro/Alfar.

- (1992b): «Relación y discurso espectaculares de televisión». En Investigaciones Semióticas. IV, AES (ed.), I, 405-410. Madrid: Visor Libros.

GutiÉRrez, F. y FuEnTE, R. de la (1992): Cómo leer a Antonio Buero Vallejo. Madrid: Júcar.

GuTIÉRREZ FlóREZ, F. (1990): «El espacio y el tiempo teatrales: Propuesta de acercamiento semiótico». Tropelias 1, 135-149.

HERMENEGILDO, A. (1987): «Conflicto dramático vs. liturgia en el teatro medieval castellano». En Studia Hispanica Medievalia, L. Teresa Valdivieso y J. H. Valdivieso (eds.), 51-59. Buenos Aires.

- (1992a): «Dramaticidad textual y virtualidad teatral: el fin de la Edad Media castellana». En Teatro y espectáculo en la Edad Media, Luis Quirante Santacruz (ed.), 99-113. Alicante: Instituto de Cultura Juan Gil-Albert/Diputación/Ajuntament d'Elx.

- (1992b): «Tello y la voz de la razón: El gracioso en El Caballero de Olmedo, de Lope de Vega». En Actas del X Congreso de la Asociación Internacional de Hispanistas, A. Vilanova (ed.), II, 993-1004. Barcelona: PPU.

Hormigón, J. A. (1991): Trabajo dramatúrgico y puesta en escena. Madrid: Publicaciones de la Asociación de Directores de Escena de España.

LARA GARRIDO, J. (1989): «Teatro y espacio escénico en Lope de Vega (La primera comedia: 1579-1597)». En La escenografia del teatro barroco, A. Egido (ed.), 91-126. Salamanca: Universidad.

LÁzaro Carreter, F. (1987): «Funciones de la figura del donaire en el teatro de Lope de Vega». En "El castigo sin venganza» y el teatro de Lope de Vega, VV. AA., 34-37. Madrid: Cátedra.

Martínez-Peñuela Virseda, A. (1991): «Las acotaciones de Rosso di San Secondo a su Marionette, che passione!». Epos VII, 455-471.

Miguel y CANUTO, J. C. de (1992): «Notas para una gramática peremiológica de los entremeses del barroco español». Lingua e Stile XXVII (1), 47-75.

MORALES ARTOLA, R. (1992): «Teatro y realidad: textos espectaculares». En Investigaciones Semióticas. IV, AES (ed.), I, 423-427. Madrid: Visor Libros.

NúÑEZ RAMOS, R. (1992): «La comunicación teatral». En Introducción a la semiótica, A. Sánchez Trigueros y J. Valles Calatrava (eds.), 51-69. Almería: Instituto de Estudios Almerienses.

OLEZA, J. (1986): «La propuesta teatral del primer Lope de Vega». Teatro y prácticas escénicas. II. La comedia, VV.AA., 251-308. Londres: Tamesis Books.

PÉREZ, M. (1992a): «Las teorías teatrales durante el período de la transición política». Teatro. Revista de Estudios Teatrales 1, 107-113.

- (1992b): «Escenografías post-teatrales. Una visión inédita del texto teatral». Teatro. Revista de Estudios Teatrales 1, 181-200. 
PÉRez BowIE, J. A. (1992): «Mecanismos de titulación en el teatro de humor de la preguerra (Aproximación semiótica)». En El teatro en España entre la tradición y la vanguardia (1918-1939), D. Dougherty y M. ${ }^{a}$ F. Vilches de Frutos (eds.), 31-43. Madrid: CSIC/Fundación Federico García Lorca/Tabacalera.

RiQuelme Pomares, J. (1990): El teatro de Miguel Hernández. Alicante: Instituto de Cultura «Juan Gil-Albert».

- (1992): «Bases de una propuesta de aproximación semiótica al teatro alegórico y social de Miguel Hernández»». En Estudios sobre Miguel Hernández, F. J. Díez de Revenga y M. de Paco (eds.), 377-399. Murcia: Universidad.

RoDRÍGuEZ LÓPEZ-VÁzQUEZ, A. (1992): «Mythe et sémiosis: Don Juan garañón/Don Juan burlador». En Signs of Humanity/L'homme et ses signes, G. Deledalle (ed.), II, 699-704. Berlín: Mouton de Gruyter.

Romera CASTILlo, J. (1992): «Semiótica literaria y teatral en España: Addenda bibliográfica IV». En Investigaciones Semióticas. IV, AES (ed.), II, 1043-1055. [«Teatro», 1052-1055.]

RUBIERA FERNÁNDEZ, J. (1992): «Japón y Occidente: ver y no ver el No». En Investigaciones Semióticas. IV, AES (ed.), I, 499-504. Madrid: Visdor Libros.

RUBIO JiMÉNEZ, J. (1989): "Anotaciones para el comentario de obras dramáticas». En Actas III Jornadas Didácticas de Lengua y Literatura para Profesores de Enseñanza Secundaria, VV.AA., 81-114. Lleida: Seminario Permanente de Lengua y Literatura Castellanas.

RUIZ RAMÓN, F. (1978): Estudios sobre teatro español clásico y contemporáneo. Madrid: Fundación Juan March/Cátedra.

— (1989): «Valle-Inclán y el teatro público de su tiempo: los signos de la diferencia». Bulletin Hispanique 91, 137-138.

- (1992): «Espacio dramático/Espacio escénico o el conflicto de códigos teatrales». En El teatro en España entre la tradición y la vanguardia (1918-1939), D. Dougherty y M. ${ }^{a}$ F. Vilches de Frutos (eds.), 23-29. Madrid: CSIC/Fundación Federico García Lorca/Tabacalera.

Salvat, R. (1987a): «Buero desde la representación escénica». En Antonio Buero Vallejo. Premio de literatura en lengua castellana «Miguel de Cervantes»1986, VV.AA., 42-46. Barcelona/Madrid: Anthropos/Ministerio de Cultura.

- (1987b): «El lenguaje escénico de Buero Vallejo». En Buero Vallejo. Cuarenta años de teatro, M. de Paco (ed.), 19-42. Murcia: Obra Cultural de Caja Murcia.

SÁNCHez TRIGUERos, A. (1992): «La poética del silencio». Teatro. Revista de Estudios Teatrales 1, 75-86.

SiRERA, J. Ll. (1992): «Sobre la estructura dramática del teatro medieval: el caso de El auto de la huida a Egipto». En Actas II Congreso Internacional de la Asociación Hispánica de Literatura Medieval, J. M. Lucía Megías et alii (eds.), II, 837-855. Alcalá de Henares: Universidad.

TORDERA, A. (1987): «Crónica y lectura escénica de El sueño de la razón». En Buero Vallejo. Cuarenta años de teatro, M. de Paco (ed.), 65-77. Murcia: Obra Cultural de Caja Murcia.

URRUTIA, J. (1977): «Estructuras cinematográficas en obras literarias (Acercamiento a una semiótica comparada)». Cinema 2002 27, 33-36.

- (1989): «Poder y sumisión del villano rico: Un conflicto dramático». En Homenaje al profesor Antonio Vilanova, A. Sotelo y M. Carbonell (eds.), 725-738. Barcelona: Universidad.

VARIOS AUTORES (1992): Dramaturgia e espectaculo (Actas 1. er Congreso Luso-Espanhol de Teatro). Coimbra. 